\title{
Promoção de uma postura científica na formação de professores: estudo exploratório
}

\author{
Scientific posture promotion in teacher training: exploratory study \\ Daniela Gonçalves*, Margarida Quinta e Costa** \\ *CEDH da UCP; ESEPF. **CIPAF do ESEPF. Porto, Portugal
}

\begin{abstract}
Resumo
Interrogar-se sobre a realidade, colocar problemas e procurar a sua solução - pressupostos do método científico - refletem, claramente, a forma como entendemos a formação em contexto real na contemporaneidade. Deste modo, ser-nos-á possível explicitar o entendimento sobre esta noção de postura científica e serão ainda apresentados dados relativos a variados momentos em que, ao longo do seu percurso académico, os estudantes são confrontados com este espírito de cultura investigativa.

Palavras-clave: formação de professores, postura científica, cultura investigativa
\end{abstract}

\begin{abstract}
Questioning the reality and solve problems - assumptions of the scientific method - reflect clearly the way we understand training in real context nowadays. This way we be able to clarify the understanding of the notion of scientific posture and we will present results relative of various moments when, along their academic path, students are faced with this spirit of investigative culture. Keywords: teacher training, scientific posture, investigative culture
\end{abstract}

Tendo em consideração que a educação e a qualificação dos recursos humanos são fatores determinantes do desenvolvimento, com este artigo, apresentar-se-á o modo encontrado na formação de futuros professores, de promoção da atividade investigativa e adoção de uma postura científica junto dos estudantes, de forma a que estes possam constituir-se como veículos de difusão de conhecimento fundamentado numa lógica de cultura investigativa. O objeto desta apresentação será a forma como provocamos nos estudantes, a vontade de investigar e os sensibilizamos para a necessidade de desenvolver uma postura científica na sua futura prática profissional. Essas funções específicas de ensinar e educar, desenvolvidas recorrendo ao saber próprio da profissão, apoiado na investigação e na reflexão partilhada da prática educativa, serão a análise presente neste texto.

Interrogar-se sobre a realidade, colocar problemas e procurar a sua solução - pressupostos do método científico - refletem, claramente, a forma como entendemos a formação em contexto real na contemporaneidade. Deste modo, ser-nos-á possível explicitar o entendimento sobre esta noção de postura científica e serão ainda apresentados dados relativos a variados momentos em que, ao longo do seu percurso académico, os estudantes são confrontados com este espírito de cultura investigativa.

\section{Contexto do estudo exploratório}

O ciclo de estudos (CE) onde se insere esta experiência Formativa/investigativa é o curso de Mestrado em Ensino do $1^{\circ}$ e do $2^{\circ}$ Ciclos do Ensino Básico. Os objetivos de aprendizagem definidos para este CE apontam para um profissional capacitado para assentar a sua prática docente num conjunto de formas de estar, viver e sentir, sistematicamente reconstruídas à luz de uma capacidade de pensamento crítico, de reflexão, de investigação e de autoanálise. Para tal, no final deste CE o estudante terá desenvolvido uma série de competências essenciais a uma prática educacional contemporânea, tais como: a) soluciona problemas, com base na aplicação prática dos conhecimentos e na análise de relações de causa-efeito, estabelecendo prioridades de atuação e aplicando, de forma estruturada e sistemática, metodologias de resolução de problemas, mesmo quando confrontado com situações de informação limitada ou incompleta; b) manifesta capacidade de pensamento crítico, através de uma capacidade de questionamento constante, e de sistemática correção de erros, no que diz respeito ao modo como raciocina e, consequentemente, como age; c) manifesta proatividade, antecipando eventuais necessidades e/ou dificuldades, para as quais procura respostas imediatas e em tempo útil, em vez de esperar passivamente por ordens ou instruções; d) gere eficazmente o tempo e sabe organizar-se em termos profissionais e de trabalho; e) evidencia constante procura de elevada qualidade no trabalho que realiza, valorizando o saber científico, o saber-fazer e o saber pedagógico; f) manifesta criatividade, identificando potencialidades novas com base nos recursos disponíveis em constante procura de elevada qualidade nos trabalhos que realiza e nos serviços que presta; g) adere, com facilidade, a eventuais mudanças que impliquem alterações de processos e metodologias de trabalho na sua área de atividade e/ou nas respetivas funções; h) dinamiza e compromete os elementos das equipas em que trabalha com objetivos mais amplos e padrões de desempenho superiores, responsabilizando-os pelos resultados obtidos e reconhecendo os seus sucessos; i) norteia a sua atuação pelo respeito de normas deontológicas e condutas moral e socialmente aceites, responsabilizando-se pelo seu próprio bem-estar, assim como pelo dos outros.

Neste âmbito, o perfil de competências desenhado para este professor de $1^{\circ}$ e $2^{\circ}$ Ciclos do Ensino Básico estruturou-se a partir da dimensão profissional, social e ética e da dimensão de desenvolvimento do ensino e da 
aprendizagem. Detalhadamente, esta experiência formativa teve em conta o perfil de competências do professor do $1^{\circ}$ e $2^{\circ}$ Ciclos de Ensino Básico em consonância com missão e planos estratégicos desta Instituição de Ensino Superior. Respeitando os normativos legais, este CE tem como objetivo geral a atualização, o aprofundamento e a especialização dos conhecimentos no ensino do $1 .^{\circ}$ e $2 .^{\circ}$ Ciclos do Ensino Básico de forma articulada e integrada, com vista à formação de docentes com uma sustentada preparação científica e académica para o exercício de atividades profissionais qualificadas.

No âmbito da formação de professores, este CE proporciona, pois, uma formação avançada na especialidade e atualizada no campo das teorias educacionais, das metodologias de investigação e intervenção educativa em vários domínios e promove o desenvolvimento de capacidades de análise educacional, de mobilização de conhecimentos teórico/metodológicos, de equacionamento das dinâmicas educativas e de intervenção educativa fundamentada.

No caso concreto do contexto da Prática de Ensino Supervisionada e de forma complementar são realizados seminários, de acordo com temáticas que, no decurso do semestre, vão emergindo como constituindo interesse e relevância, de forma a disponibilizar apoio teórico-prático aos formandos em áreas específicas de atuação. Para além disto, estes seminários de apoio ao estágio contemplam atividades complementadas com seminários de apoio à Intervenção Educativa, privilegiando o processo, "em especial num regime democrático, sendo essencial existir espaço, tempo e meios para o debate informado, seja entre os protagonistas de pontos de vista concorrentes e conflituantes (...). E para esse debate é essencial a disponibilidade de informação, em quantidade, qualidade e diversidade, para que todos os interessados possam formar a sua opinião e que lhes seja possível tomar, a outro nível, tomar decisões fundamentadas” (Guinote, 2012: 9).

\section{Procedimentos metodológicos}

A abordagem qualitativa é coerente com um paradigma interpretativo de investigação que, segundo alguns autores (Bogdan \& Biklen, 1994; Lessard-Hébert, Goyette \& Boutin, 1994), consiste em conhecer o sujeito, atendendo ao contexto, procurando compreender os diversos fenómenos, sendo resultante do crescente interesse pelas questões educacionais.

Situando-se as nossas preocupações num campo relativamente recente, com convulsões e constantes alterações legislativas, não existem ainda muitos estudos elaborados no nosso país, que possam sustentar a nossa investigação, pelo que a iremos situar no domínio de um estudo exploratório. De acordo com Yin (2005:183), “um caso exploratório(...) pode tratar do tema ou do problema que está sob exploração, dos métodos exploratórios, das descobertas feitas a partir da exploração e das conclusões (para pesquisa adicional)". Mais ainda, salientamos a ideia de Yin (2005) de que o estudo deste caso surge na sequência de se pretender conhecer melhor um fenómeno, uma situação, que deve ser significativa, sendo amplamente utilizado nas ciências sociais. No entanto, nesta experiência, foi nossa pretensão realizar o estudo de um caso, quer pela natureza do fenómeno (cingido a um espaço próprio), quer pelos participantes (amostra de conveniência), quer pela questão temporal.

Guba e Lincoln (1994) definem paradigma como um sistema de conceções básicas que um indivíduo possui, permitindo-lhe uma dada perspetiva do mundo e, consequentemente, da sua natureza, sendo através desse sistema que o indivíduo percebe o seu lugar no mundo e o tipo de relações possíveis que pode estabelecer com ele e com as suas partes. Essas conceções básicas que caraterizam um paradigma de investigação podem ser sintetizadas através das respostas dadas a três questões essenciais e interdependentes: (a) qual é a forma e a natureza da realidade e o que se pode conhecer acerca dela? (questão ontológica); (b) qual é a natureza das relações entre aquele que conhece, ou quer conhecer, e aquilo que pode ser conhecido? (questão epistemológica); e (c) como procede aquele que quer conhecer para descobrir o que crê poder ser conhecido? (questão metodológica).

O estudo exploratório que apresentaremos envolveu dois estudantes a frequentar o $2^{\circ}$ ano do Mestrado de Formação de Professores - especialidade em Ensino do $1^{\circ}$ e do $2^{\circ}$ Ciclos do Ensino Básico na Escola Superior de Educação de Paula Frassinetti, no corrente ano letivo. No âmbito da Prática de Ensino Supervisionada (centrada no $2^{\circ}$ Ciclo do Ensino Básico), o estágio ocorreu numa instituição de ensino privado.

Os estudantes foram solicitados a conceber propostas de intervenção adequadas ao contexto do $2^{\circ}$ Ciclo de Ensino Básico, nomeadamente, neste caso, na área das Ciências Naturais, produzindo planificações e reflexões sobre a sua intervenção educativa.

\section{Resultados do estudo exploratório}

A postura científica, que pretendemos promover nos estudantes, tem obrigatoriamente de se construir pela capacidade de refletir. A reflexão contínua sobre a prática e focalizada de modo a permitir o desenvolvimento desta maneira de estar na educação não é um processo empírico mas construído com os outros, de um modo orientado e partilhado. Assim, durante o período do estágio profissionalizante a supervisora pedagógica colocou, quinzenalmente, desafios à reflexão, orientando os estudantes com algumas questões. Este acompanhamento próximo dos estudantes durante o seu percurso formativo promove momentos de reflexão, cada vez mais profundas e estruturantes da sua prática profissional. Os desafios foram do tipo: "Que objetivos defini até agora? O que aprendi até agora?” (DO1)

Numa primeira abordagem, os estudantes, pelo facto de ainda não terem lecionado nenhuma aula, refletem sobre as suas expectativas e receios, nomeadamente na relação com os professores cooperantes e receio de não ter competência para as tarefas que os esperam. Expressam a preocupação de conhecer os alunos, as suas dificuldades 
e particularidades, assim como a organização da escola: "propus-me a atingir dois objetivos: conhecer melhor a turma e a Instituição” (BR1). Observam e registam alguns comportamentos dos alunos e as respostas por parte do professor cooperante, assimilando-as como exemplos a seguir: "os professores deste colégio não respondem diretamente às questões dos alunos” (CR1), assumindo, por vezes, uma escrita descritiva como "a docente utiliza muitos esquemas e desenhos” (CR1). A supervisora pedagógica comenta, orientando com reforço positivo: "É capaz de melhor...” (DO2).

Nas reflexões seguintes, os estudantes descentralizam a atenção neles próprios e passam a escrever reflexões nas quais fundamentam as suas afirmações e opções com referências bibliográficas, como: “a estagiária sentiu necessidade de alterar o tipo de planificação...“[...] o modelo de planificação seguido é importante, pois reflete a maneira como foi concebida a aula [...]" (Braga, Vilas-Boas, Freitas \& Leite, 2004:26)” (BR4). A orientação dada pela supervisora pedagógica passa a ser direcionada para a prática, como por exemplo: "Problemática(s) identificada(s) ao longo do processo (planificação, implementação, ...)” (DO3) deixando de ser colocada orientação na quinta semana. Toda a informação posterior remete para artigos científicos ou vídeos que possam desafiar as conceções dos estudantes face à educação, promovendo só por si, reflexões sobre a construção da profissionalidade docente, quando o estudante "acredita que pode fazer a diferença na vida destas crianças" (B9) ou afirma convicta que "urge mudar comportamentos, apurar os objetivos que faltam cumprir" (C5).

Numa postura científica, transferem para as suas planificações as competências que desenvolveram, proporcionando aos alunos momentos de aprendizagem, equivalentes aqueles por eles vivenciados. A postura da supervisora desafiando os estudantes com questões, de modo que cada um desenvolve o seu próprio percurso, reflete-se depois nas suas práticas: “o que vos sugere esta imagem?” (B1) ou colocando uma Questão-Problema como desafio à experimentação - “qual é a preferência da minhoca quanto à luz e humidade do meio?” (C1).

$\mathrm{Na}$ análise reflexiva sobre as planificações dos estudantes, verificamos que se preocupam em criar momentos de observação, de modo que o conhecimento não seja transmitido pelo professor mas apreendido do aluno. Nas suas aulas, recorrem, por exemplo, à visualização de um vídeo sobre a gravidez, pedindo aos alunos que selecionem os conceitos abordados (B1) ou a observação dos resultado de uma experiência como a influência da humidade no comportamento das minhocas (C1). Na pesquisa realizada pelos alunos, a pares, sobre os conceitos selecionados verifica-se que o estudante estagiário tem preocupação com a correção científica dos significados, pois escreve no quadro as informações fornecidas pelos alunos e só em seguida os podem passar para o caderno, como documento de revisão para estudarem posteriormente. $\mathrm{Na}$ atividade experimental planeia momentos de reflexão sobre os resultados para posterior “discussão orientada com questões” (3C1). As aulas de ciências naturais foram, na sua maioria, de ensino experimental e, por isso, mais centrada no aluno, que pode partilhar as previsões dos resultados "num momento destinado à discussão de ideias” (BR6), permitindo a confrontação entre as suas conceções empíricas e os resultados científicos da atividade experimental.

O momento do registo, desenvolvido no percurso formativo do estudante estagiário quer na reflexão quer na avaliação dos alunos, é transportado para a escrita dos conceitos ou dos resultados por parte dos alunos.

A atitude proativa dos estudantes surge pela autonomia com que pensam a sua prática no sentido de a melhorarem para benefício dos próprios alunos. Ora, o estagiário construiu uma grelha de avaliação do seu desempenho a ser preenchida pelos alunos, "pois são eles o foco de todo o trabalho realizado" (B9), ou envolve-se no desenvolvimento de um projeto de ensino experimental de ciências, lançando desafios extracurriculares, pretendendo a "criação de atividades ambiciosas e significativas para os alunos” (CR4).

Entre os estagiários definiu-se a possibilidade de partilharem as suas reflexões assim como as planificações e recursos utilizados de modo que o percurso formativo de cada estudante estagiário pode ser, se ele o quiser, construído entre pares e todos com a supervisora pedagógica. Esta partilha nem sempre é facilmente aceite num contexto social de grande competitividade mas, a supervisora fundamenta esta opção pelo desenvolvimento cooperativo que daí advém, sugerindo também uma grelha de acompanhamento da prática profissional, a preencher pelo estudante que assiste à aula do par pedagógico, avaliando indicadores de conhecimento, desempenho científico-pedagógicos e de interação com os alunos. Neste momento avaliativo, em que o estudante assume o papel de amigo crítico, pretende-se sinalizar pontos fortes e fracos daquela intervenção, estimulando a melhoria da prática de ambos os estudantes.

Com o mesmo pressuposto, os estudantes envolvem os alunos na partilha dos conhecimentos e na interajuda pedindo "a dois alunos que já tinham terminado (e que têm bom aproveitamento), para ajudar outros colegas sem que lhes dissessem o resultado" (BR1). O estímulo ao trabalho colaborativo foi desenvolvido também na possibilidade de os alunos obterem uma "estrela (...) se num espaço de tempo indicado, todos os alunos conseguirem passar do nível 5" pelo que "os alunos que terminarem primeiro, têm a tarefa de apoiar os colegas com dificuldades" (CR3). Esta capacidade de colocar as suas competências ao dispor do grupo forma os alunos numa vertente cívica e social, competências fundamentais a desenvolver na formação de qualquer cidadão. Deste modo, os estudantes conseguiram encontrar respostas eficientes para as inquietações resultantes da sua postura interrogativa sobre a realidade: "sinto que tenho que fazer algo para os (alunos) ajudar" (BR1) disponibilizando-se para "prestar apoio aos alunos (...) fora do horário de estágio" (BR6) ou o desenvolvimento do projeto de ciencias, extracurricular, que pretende "proporcionar aos alunos as condições necessárias para que estes desenvolvam um raciocínio crítico" (CR6) e "retirarem: o prazer da investigação; da descoberta e da pesquisa" (CR6), estimulando-os na 
construção do conhecimento.

Assumindo “o papel de mediador, deixando as restantes funções ao cargo dos alunos” (BR10), a supervisora pedagógica, durante o percurso de formação em contexto de prática pedagógica dos estudantes, também reflete sobre a sua prática, pois compromete-a e responsabiliza-a.

\section{Considerações Finais}

O modo como provocamos os estudantes, colocando questões e comentando os documentos orientadores que produziram, promove a atividade investigativa, pois estes passam a consolidar as suas afirmações, recorrendo a referências bibliográficas. Pelo acompanhamento do seu percurso formativo desenvolveram uma postura científica, observando, questionando-se, pesquisando e refletindo, que se transferem para a sua prática em sala de aula, nomeadamente na área das ciências. Os estudantes, refletindo sobre a sua prática, sentiram "necessidade de arranjar estratégias motivadoras para atrair e chegar aos alunos” (BR3), pois concluem que "o fascínio de ensinar nunca é maçador. Estamos em contínuo desafio [...] a ponderar e a refletir sobre o nosso desempenho [...]” (Alan Haigh, 2010:179).

A análise preliminar do percurso dos estudantes estagiários permite-nos compreender que desenvolveram uma postura científica, com a orientação da supervisora pedagógica, valorizando o conhecimento, pois consideram que "todos os conteúdos lecionados (devem ser) dominados pelo professor" (CR5), o envolvimento dos alunos no seu processo de aprendizagem, porque "importa que estes (alunos) sejam envolvidos no planeamento dos desafios e que haja liberdade nessa participação” (CR6), e a consciência das suas limitações, porque "sabe que vai errar em muitas situações ao longo da vida” (BR10), perspetivando um futuro responsável e num espírito de cultura investigativa, porque "só assim nos poderemos tornar melhores naquilo que fazemos" (BR10).

\section{Referências}

Bogdan, R. \& Biklen, S. (1994). Investigação qualitativa em educação. Uma introdução à teoria e aos métodos. Porto: Porto Editora.

Braga, F., Vilas-Boas, M., Freitas Ma . \& Leite, C. (2004). Planificações novos papéis, novos modelos. Porto: Edições Asa.

Guba, E. G., \& Lincoln, Y. S. (1994). Competing paradigms in qualitative research. In N. K. Denzin e Y. S. Lincoln (Eds.), Handbook of qualitative research (pp. 105-117). Thousand Oaks, CA: Sage.

Guinote, P. (2012). O Direito a Escolher, O Dever de informar. In Raymond M., Steen, S. e Homem Cristo, A., As Novas Escolas. Lisboa: Fundação Francisco Manuel dos Santos.

Haigh, A. (2010). A arte de ensinar. Alfragide: Academia do Livro.

Lessard-Hébert, M. Goyette, G. \& Boutin, G. (1994). Investigação Qualitativa: Fundamentos e Práticas. Lisboa: Instituto Piaget.

Yin, R. (2005). Estudo de Caso-Planejamento e Métodos. $3^{\mathrm{a}}$ Edição. Porto Alegre: Bookman. 